\title{
PESQUISA EM EDUCAÇÃO AMBIENTAL E POLÍTICAS PÚBLICAS: DESAFIOS POLÍTICOS E EPISTEMOLÓGICOS
}

\author{
Luiz Carlos Santana ${ }^{1}$ \\ Rodrigo de A. C. Lamosa ${ }^{2}$
}

\begin{abstract}
Resumo
O presente artigo resulta da proposta de realizar o registro sobre as reflexões elaboradas pelos pesquisadores participantes do Grupo de Discussão de Pesquisas (GDP) sobre Pesquisa em Educação Ambiental e Políticas Públicas, ocorrido durante o VIII EPEA (Julho de 2015 - Rio de Janeiro/RJ). O GDP foi formado a partir dos quatorze trabalhos aprovados, que foram apresentados pelos autores e debatidos pelos participantes. Os coordenadores do GDP apresentaram uma sistematização sobre temas, objetivos e metodologias do conjunto dos trabalhos apresentados, identificando uma rica variedade entre eles. A sistematização foi debatida pelos participantes e, decorrente do debate, uma série de questões de pesquisa foi organizada com o objetivo de forjar uma agenda de investigação, respeitando a diversidade de abordagens e procedimentos teórico-metodológicos. O foco da discussão do GDP foi a gestão pública da Educação Ambiental e as questões de pesquisa que derivam das disputas travadas, tanto nas definições epistemológicas, quanto na materialidade das políticas públicas no contexto de reforma do Estado brasileiro. O artigo conclui ressaltando o conjunto de temas candentes de pesquisa, identificado pelos participantes do GDP.
\end{abstract}

Palavras-chave: Pesquisa em Educação Ambiental. Políticas Públicas. Gestão Pública da Educação Ambiental.

\section{RESEARCH IN ENVIRONMENTAL EDUCATION AND PUBLIC POLICY: POLITICAL AND EPISTEMOLOGICAL CHALLENGES}

\begin{abstract}
The present article is the result of the proposal to perform the registry about the reflections developed by researchers participating in the research discussion group (GDP) on research in environmental education and public policy, occurred during the VIII EPEA (July 2015 - Rio de Janeiro/RJ). The GDP was formed from the fourteen papers were presented by the authors approved and discussed by the participants. The coordinators of the GDP showed a systematization on themes, objectives and methodologies of all papers presented by identifying a rich variety among them. Systematization was discussed by the participants and stemming from the debate, a number of research questions was organized with the aim of forging an agenda for research, respecting the diversity of approaches and theoreticalmethodological procedures. The focus of the discussion of GDP was the public management of environmental education and research issues that derive from wrangling fought in epistemological definitions, and the materiality of public policies in the context of reform of the State. The article concludes pointing out the set of burning issues of research, identified by the participants of the GDP.
\end{abstract}

\footnotetext{
${ }^{1}$ Professor Assistente Doutor II do Instituto de Biociências, UNESP - Univ Estadual Paulista, Rio Claro, Departamento de Educação, Programa de Pós-graduação em Educação (PPGE). 1uizcs@ @rc.unesp.br

2 Professor Doutor da Universidade Federal Rural do Rio de Janeiro e do Programa de Pós-Graduação em Educação, Demandas Populares e Contextos Contemporâneos (PPGEduc). rodrigo1281@ yahoo.com.br
} 
Keywords: Environmental Education Research. Public Policies. Public Administration of Environmental Education.

\title{
INVESTIGACIÓN EN EDUCACIÓN AMBIENTAL Y POLÍTICAS PÚBLICAS: DESAFÍOS POLÍTICOS Y EPISTEMOLÓGICOS
}

\begin{abstract}
Resumen
El presente artículo es el resultado de la propuesta para realizar el registro de las reflexiones desarrolladas por los pesquisidores participantes del Grupo de Discusión de Pesquisas (GDP) acerca de la investigación en educación ambiental y políticas públicas, durante el VIII EPEA (julio de 2015). El GDP se formó a partir de los catorce trabajos aprobados, que fueron presentados por los autores y discutidos por los participantes. Los coordinadores del GDP trajeron una sistematización sobre los temas, los objetivos y metodologías que forman el cuerpo del trabajo presentado, identificando una rica variedad entre ellos. Sistematización se debatió por los participantes y una serie de preguntas de investigación se organizó, con el objetivo de forjar una agenda de pesquisa, respetando la diversidad de enfoques y procedimientos teórico-metodológicos. El foco de la discusión del GDP fue la gestión pública de la educación ambiental y los temas de investigación consiguientes de las discusiones emprendidas, sea en definiciones epistemológicas, sea sobre la materialidad de las políticas públicas en el contexto de la reforma del estado. El artículo concluye, señalando el conjunto de temas candentes de investigación, identificados por los participantes del GDP.
\end{abstract}

Palabras-clave: Investigación en Educación Ambiental. Políticas públicas. Administración Pública de la Educación Ambiental.

\section{Introdução}

O Grupo de Discussão de Pesquisa (GDP) sobre Pesquisa em Educação Ambiental e Políticas Públicas, constituído a partir de 2009, vem se consolidando enquanto espaço fundamental de reflexão e socialização de resultados de pesquisas desenvolvidas no meio acadêmico. Este GDP tem se notabilizado pela qualidade dos debates promovidos pelos pesquisadores que, a cada edição, fortalecem a organização de um campo de investigação marcado não apenas pela diversidade teórica e metodológica, mas, também, pelos desafios políticos e epistemológicos que se renovam a cada edição do Encontro de Pesquisa em Educação Ambiental (EPEA). Assim, no contexto de cada novo EPEA, o referido GDP tem se fortalecido, constituindo-se em espaço estratégico de reflexão e organização de agendas de pesquisa para novos e experientes pesquisadores.

Este artigo tem o objetivo de socializar, de forma sistematizada, as reflexões realizadas pelos pesquisadores participantes do GDP - Pesquisa em Educação Ambiental e Políticas Públicas - no VIII EPEA, realizado na Universidade Federal do Estado do Rio de Janeiro (UNIRIO), em 20153. Nesse sentido, este trabalho elabora uma síntese das discussões empreendidas no interior do grupo, além de apresentar as questões e temas propostos pelos pesquisadores participantes, visando futuras investigações. Estes complementam uma agenda de pesquisas que o GDP tem organizado, desde 2011, a partir da realização do VI EPEA.

A primeira versão do EPEA ocorreu no campus da Unesp de Rio Claro - SP, em julho de 2001, e, no mesmo mês de 2015 foi realizada a oitava edição do evento de pesquisa, dessa

\footnotetext{
${ }^{3}$ Agradecemos a colaboração de todos pesquisadores participantes do GDP - Pesquisa em Educação Ambiental e Políticas Públicas - durante o VIII EPEA, pelas discussões empreendidas no grupo que, de certa forma, estão presentes neste artigo. Agradecemos, especialmente, à Yvaga Poty Penido pelo trabalho de relatora.
} 
vez, na cidade do Rio de Janeiro, RJ. ${ }^{4}$ Os GDPs foram organizados a partir do III EPEA, realizado no campus da USP de Ribeirão Preto, SP, em 2005, configurando, em definitivo, um espaço fundamental de discussão e de socialização dos resultados de pesquisa na área da educação ambiental, a partir de diferentes eixos temáticos.

O GDP Pesquisa em Educação Ambiental e Políticas Públicas foi organizado, pela primeira vez, no V EPEA, realizado no campus da UFSCar, em São Carlos, SP, em 2009 (GUIMARÃES; OLABARRIAGA; TONSO, 2009). No V EPEA, dos 90 trabalhos aceitos para apresentação, 20 deles (23\% do total) foram apresentados no GDP de Pesquisa em Educação Ambiental e Políticas Públicas. No VI EPEA, realizado no campus da USP de Ribeirão Preto, em 2011, dos 85 trabalhos de pesquisa sobre educação ambiental apresentados, 11 deles $(12,94 \%)$ foram efetivamente inscritos e apresentados nesse GDP (FERRARO, 2012, p. 136). No VII EPEA, o número de trabalhos apresentados no GDP voltou a crescer. Foram inscritos 21 trabalhos para apresentação, que representaram uma porcentagem de 20,19\% do total de 104 trabalhos inscritos naquela ocasião (SANTANA, 2014, p.4). Em 2015, no VIII EPEA, foram apresentados 14 trabalhos no GDP, perfazendo 12,96\% de um total de 108 trabalhos inscritos. Apesar da oscilação, o GDP de Pesquisa em Educação Ambiental e Políticas Públicas, em razão da qualidade dos trabalhos apresentados e debates realizados, tem se caracterizado pela capacidade reflexiva e por uma demanda significativa por parte de jovens e promissores pesquisadores.

Durante o V EPEA, realizado em 2009, os participantes do GDP, então denominado de EA e Políticas Públicas, realizaram discussões a partir de um texto produzido previamente pela coordenação, cujo objetivo consistia em "trazer algumas considerações sobre políticas públicas e educação ambiental e oferecer um campo de reflexões para que o Grupo de Discussão de Pesquisas em Políticas Públicas e Educação Ambiental no V EPEA pudesse se construir num espaço de diálogo entre pesquisadores dessa área", em busca de "identificar as principais linhas de pesquisa em Educação Ambiental e políticas públicas, o estado da arte dessas linhas e o estímulo à criação e fortalecimento de grupos de pesquisadores visando à articulação entre essas linhas de pesquisa" (GUIMARÃES; OLABARRIAGA; TONSO, 2009, p. 216).

Já no VI EPEA, realizado em 2011, as perguntas orientadoras presentes no registro feito sobre o GDP, que passou a ser, então, denominado de Pesquisa em Educação Ambiental e Políticas Públicas, foram as seguintes: "o que o VI EPEA nos revela sobre esse campo emergente de pesquisa? Que tendências temáticas e metodológicas podem ser percebidas? Que orientações podem ser destacadas para as políticas? (FERRARO JR, 2012, p. 135).

Por sua vez, no VII EPEA, realizado em 2013, as discussões ocorridas no âmbito do GDP de Pesquisa em Educação Ambiental e Políticas Públicas estiveram circunscritas aos aspectos vinculados à natureza do Grupo, ou seja, discussão de pesquisas produzidas sobre o tema e encaminhadas para o evento, procurando, a partir destas, explorar as principais tendências percebidas. Constatando a riqueza da discussão dos trabalhos na variedade dos temas, dos objetos, das questões de pesquisa e dos procedimentos teórico-metodológicos usados, dois focos nortearam as discussões empreendidas: os entendimentos de educação ambiental e os entendimentos de políticas públicas presentes nos trabalhos.

No VIII EPEA, em 2015, a coordenação do GDP propôs, como dinâmica inicial, que o grupo de pesquisadores participantes apresentasse sucintamente suas pesquisas, procurando estabelecer relações com os temas candentes de pesquisas no campo das políticas públicas, identificados a partir de uma sistematização, elaborada pelos coordenadores, do conjunto de trabalhos inscritos no GDP. 
Diante dos desafios postos aos participantes do GDP frente ao processo de reforma do Estado brasileiro que introduz na administração pública modelos empresariais de gestão do trabalho, os autores deste artigo avaliam que as discussões realizadas no referido espaço vêm se constituindo um patrimônio intelectual da educação ambiental brasileira. Sendo assim, este artigo apresenta o resultado desse esforço coletivo de reflexão produzido pelos pesquisadores que compuseram, no VIII EPEA, o GDP Pesquisa em Educação Ambiental e Políticas Públicas.

\section{VIII Encontro de Pesquisa em Educação Ambiental}

Na oitava edição do EPEA, o GDP Pesquisa em Educação Ambiental e Políticas Públicas reuniu os autores dos trabalhos aprovados e pesquisadores inscritos como ouvintes ou com trabalhos inscritos em outros grupos, interessados, contudo, na temática do grupo. $\mathrm{O}$ GDP foi formado a partir dos quatorze trabalhos aprovados, que foram brevemente apresentados pelos autores e debatidos pelos participantes.

Os coordenadores expuseram uma sistematização sobre a riqueza da variedade de temas, objetivos e metodologias que formaram o conjunto de trabalhos aprovados para o GDP. A sistematização foi debatida pelos participantes e uma série de questões de pesquisa foi organizada com o objetivo de forjar uma agenda de investigação, respeitando a diversidade de abordagens e procedimentos teórico-metodológicos existentes no campo de pesquisas.

A partir das apresentações iniciais, o foco da discussão do GDP, por consenso estabelecido no interior do próprio grupo, foi a gestão pública da Educação Ambiental e as questões de pesquisa que derivam das disputas travadas, tanto nas definições epistemológicas, quanto na materialidade das políticas públicas no contexto de reforma do Estado brasileiro. A importância e atualidade do foco definido pelo grupo expressam a preocupação dos pesquisadores presentes relativa aos processos que vêm redefinindo, nas últimas décadas, a dimensão pública, a participação da Sociedade Civil na elaboração das políticas públicas e a própria noção de democracia e do estado de direito. Nesse sentido, os trabalhos aprovados no GDP foram reunidos, a partir da sistematização realizada pelos coordenadores, em sete eixos temáticos: 1) Educação Ambiental e turismo; 2) Unidades de conservação; 3) Licenciamento ambiental; 4) Educação Ambiental no contexto escolar; 5) Políticas de Educação Ambiental (nas esferas Federal, Estadual e Municipal); 6) Educação Ambiental e o controle social das políticas públicas; 7) Estado da arte do campo. Os trabalhos foram divididos entres esses eixos temáticos da seguinte maneira (Quadro 1). 


\section{TEMAS PESQUISADOS}

\section{EA e turismo - Gestão e Turismo Rural. (Tr85)}

2. Unidades de Conservação - Formação socioambiental nos Conselhos Gestores para fortalecer a Gestão Pública; Educação Ambiental e Turismo como ferramenta de gestão Unidades de Conservação; EA crítica relacionada a modelos de criação e gestão de Unidade de Conservação; (Tr15 - Tr121 - Tr207)

3. Licenciamento Ambiental - Programa de EA com Comunidades Pesqueiras (PEAC)/ (Tr32); Projeto de EA no licenciamento do Petróleo e a Gestão Ambiental (Tr 32 - Tr178).

4. EA no contexto escolar - EA e as políticas públicas na rede municipal de Teresópolis; Os projetos "escolas sustentáveis" no município de São João da Barra - RJ; A gestão das águas no programa "Vamos Cuidar do Brasil com Escolas Sustentáveis" (Tr13 - Tr119 $\operatorname{Tr} 132)$.

5. Políticas de EA (Federal, Estadual e Municipal) - Política estadual de educação ambiental - lei no 6882/2010 e uma análise crítica do currículo; Política Municipal de EA do Rio de Janeiro (RJ) e de Ribeirão Preto (SP); (Tr12 - Tr27 - Tr193).

6. EA e o controle social das políticas públicas - Educação ambiental crítica enquanto instrumento para o controle social dos royalties $(\operatorname{Tr} 33)$.

7. Estado da Arte e Pesquisa em EA -Pesquisa em educação ambiental e políticas públicas: processos de formulação e implementação abordados nas dissertações e teses brasileiras (Tr26).

Quadro 1 - Eixos temáticos dos trabalhos apresentados no GDP de Pesquisa em Educação Ambiental e Políticas Públicas - VIII EPEA - Rio de Janeiro, jul/2015.

Fonte: Coordenadores do GDP.

Em relação aos temas explorados pelos trabalhos do GDP, alguns aspectos se destacam. O primeiro diz respeito à abrangência temática que abarca trabalhos que empreenderam reflexões acerca de problemas de natureza específica, como é o caso do trabalho que analisa a gestão turística de um hotel situado em área de conservação ambiental (Tr85), até investigações de natureza mais ampla sobre políticas e programas nacionais $(\operatorname{Tr} 27$; Tr132). Esse movimento de análise de temas, dos mais específicos para os mais amplos, é também notado quando identificamos trabalhos que analisam leis municipais de educação ambiental $(\operatorname{Tr} 27$; $\operatorname{Tr} 193)$, outros analisam leis estaduais $(\operatorname{Tr} 12)$ e ainda outros focam suas análises em leis federais (Tr207).

Chama a atenção, no conjunto dos trabalhos apresentados, o fato de que 3 deles, ou seja $21,42 \%$, tematizam a educação ambiental no processo de licenciamento de petróleo e gás. Tais trabalhos assumem perspectiva de educação ambiental crítica e tem como foco de investigação a produção de conhecimento em um programa específico $(\operatorname{Tr} 32)$, ou os reflexos dos projetos de educação ambiental no processo de licenciamento $(\operatorname{Tr} 178)$ ou ainda controle social dos royalties resultantes dos processos de licenciamento (Tr33). É indispensável destacar que, apesar das especificidades, no conjunto os trabalhos tiveram preocupação de relacionar seus objetos de pesquisa com aspectos da totalidade histórica dos processos em que estão inseridas as singularidades de cada investigação. Esse reconhecimento favoreceu o estabelecimento de relações entre os trabalhos do GDP, articulando, por intermédio da história, os debates do campo de pesquisa.

Os objetivos dos trabalhos expressam a diversidade que compõe o amplo conjunto de pesquisas apresentadas no GDP. No eixo Educação Ambiental e turismo, o trabalho (Tr085) apresentado teve o objetivo realizar uma análise sobre o turismo rural no município de Engenheiro Paulo de Frontin/RJ, tendo como objeto de análise o Hotel Fazenda Santa Bárbara. 
Os trabalhos identificados com o eixo temático Unidades de Conservação tiveram entre seus objetivos: (Tr015) - analisar o processo formativo articulado à fiscalização em Unidades de Conservação (UC) no estado de São Paulo; (Tr217) - discutir teoricamente a educação ambiental em unidades de conservação, tendo em vista o contexto histórico de criação e gestão desses espaços públicos integrantes de territórios instituídos; (Tr121) refletir sobre as potencialidades e limites da Educação Ambiental, em um contexto das ações realizadas em unidades de conservação.

Os trabalhos do eixo temático Licenciamento Ambiental propuseram análises sobre processos de grande impacto social. Um dos trabalhos (Tr032) propõe um ensaio teórico que, visando um processo emancipatório, reflita sobre a articulação entre pesquisa e educação ambiental no licenciamento ambiental. Esse trabalho está desenhado no contexto do Programa de Educação Ambiental com Comunidades Costeiras (PEAC), condicionante de licenciamento ambiental dos empreendimentos marítimos da Petrobras na região de Sergipe e Alagoas. Outro trabalho ( $\operatorname{Tr} 178)$ inserido nesse eixo temático objetivou analisar os projetos de educação ambiental no licenciamento do petróleo e a gestão ambiental, propondo desvelar os reflexos desses projetos para além dos resultados apresentados oficialmente, sobretudo acerca da participação social na gestão ambiental dos seus territórios.

No eixo temático Educação Ambiental no contexto escolar os trabalhos indicaram entre seus objetivos: refletir sobre o programa governamental das escolas sustentáveis, no sentido de compreender as possíveis articulações entre os projetos educativos do município de São João da Barra - RJ com os conflitos ambientais dos territórios onde estão situadas as escolas (Tr119); analisar a inserção da educação ambiental nas escolas públicas do município de Teresópolis, no estado do Rio de Janeiro (Tr013); refletir sobre como as questões socioambientais que envolvem a água se inserem no programa Vamos Cuidar do Brasil com Escolas Sustentáveis (Tr132).

Os trabalhos no eixo Políticas de Educação Ambiental tiveram entres os objetivos: analisar as concepções de currículo presentes na Política Sergipana de Educação Ambiental, no pensar e no fazer educativo socioambiental em sintonia com a EA Crítica (Tr012); identificar e analisar problemas existentes no texto da lei da Política Municipal de Educação Ambiental de Ribeirão Preto (Tr027); analisar as disputas e correlação de forças em torno da Política Municipal de EA do Rio de Janeiro (Tr193).

Quanto ao eixo temático Educação Ambiental e o controle social das políticas públicas, o único trabalho (Tr033) apresentado propôs refletir sobre a articulação entre a educação ambiental e o controle social, exercido particularmente sobre três municípios sergipanos, quais sejam: Barra dos Coqueiros, Pacatuba e Pirambu. No eixo Estado da Arte do campo, o trabalho (Tr026) apresentou pesquisa visando explicitar os processos de formulação e implementação de políticas públicas de educação ambiental abordados em dissertações e teses de educação ambiental no Brasil.

Em relação aos referenciais teórico-metodológicos, constatou-se a presença marcante do materialismo histórico-dialético, notado desde as edições anteriores do GDP (SANTANA, 2014; FERRARO, 2012). O referencial é advogado por trabalhos em todos os eixos temáticos. Entre os autores do campo da educação ambiental os mais citados também se situam no âmbito do materialismo histórico-dialético, como Loureiro (2003, 2012), Loureiro et. al. (2005), Quintas (2006, 2009), Tozoni-Reis (2011), Lamosa (2010), Anello (2009). Outros autores, também considerados de perspectiva crítica, foram referenciados, tais como Guimarães (2004, 2009), Layrargues (2002, 2012), Layrargues e Lima (2011), Sorrentino (2005) e Carvalho (2001, 2004).

Entre os aspectos metodológicos, a diversidade de instrumentos de coletas de dados e de procedimentos de análise também é característica do conjunto de trabalhos apresentados no GDP durante o VIII EPEA. Entre os instrumentos de coleta utilizados nos trabalhos, 
destacaram-se a pesquisa histórica (Tr121), pesquisa documental $(\operatorname{Tr} 207, \operatorname{Tr} 027, \operatorname{Tr} 33$, Tr132), observação (Tr015), entrevista semiestruturada ( $\operatorname{Tr} 085, \operatorname{Tr} 193, \operatorname{Tr} 178)$ e aplicação de questionário (Tr013, Tr015). Dentre os procedimentos de análise, destaca-se a análise de conteúdo (Tr026, Tr119) e análise do discurso (Tr012).

\section{Da agenda de pesquisa}

O debate acerca dos temas apresentados pelos trabalhos inscritos no GDP - Pesquisa em Educação e Políticas Públicas deu continuidade a um processo iniciado na VI edição do EPEA, realizada em 2011, de organização de uma agenda de temas de pesquisas proposta pelos participantes do grupo. Naquela ocasião, foram propostos oito temas: 1) Os conceitos de Estado e sociedade civil nas políticas públicas de educação ambiental; 2) Limites e estratégias para que as políticas públicas possam se constituir como políticas de Estado, políticas estruturantes, mais densas e menos instáveis; 3) As tensões indivíduo-instituição na formulação das políticas públicas; 4) O lugar das políticas públicas em educação ambiental no Estado (o quão estratégicas elas são, se são marginais... que condições têm para sair desse lugar mais marginalizado?). 5) A relação das políticas públicas de educação ambiental com outras políticas públicas, destacadamente, as de educação (reiteradas várias vezes), mas também as demais políticas sociais, de saneamento, de saúde etc.; 6) Estudo das condições objetivas das políticas públicas de educação ambiental (como se constroem as equipes, orçamentos, quais são as condições de se desenvolver políticas); 7) Mais estudos de caso (pontuais e mais abrangentes - municipais, estaduais e federais) da materialização das políticas públicas de educação ambiental, com vistas a traçar diagnósticos e mapeamentos e 8) Os diferentes interesses da sociedade civil em jogo na definição das políticas de educação ambiental (relação das políticas de EA com as demandas dos movimentos sociais, sobretudo, ligados à educação).

Em 2013, no VII EPEA, foram elencados, além dos temas acima referidos, mais três eixos temáticos: 9) Pesquisas enfocando os aspectos ambientais e educacionais, em especial aquelas que avaliam os resultados e/ou consequências das políticas públicas quanto a tais aspectos; 10) Análise dos resultados das políticas públicas (considerando a carência na divulgação dos resultados das políticas públicas pelo próprio Estado); 11) Buscar explicitar elementos resultantes da investigação que indiquem perspectivas de uma efetiva emancipação humana, evitando, com isto, a desilusão e o desânimo (tanto para o pesquisador quanto para os sujeitos das pesquisas desenvolvidas.

No VIII EPEA, foram propostos onze novos eixos temáticos: 12) Pesquisas que caracterizem a Gestão Ambiental Pública no Estado brasileiro; 13) Pesquisas que investiguem os instrumentos de participação que caracterizam a Gestão Ambiental Pública; 14) Mais estudos sobre a atuação dos sujeitos prioritários da Gestão Ambiental Pública; 15) Investigações sobre a formulação das propostas de Gestão Ambiental Pública (quem são os sujeitos que vem realizando a formulação das políticas públicas para a Gestão Ambiental Pública? Como esses sujeitos vêm atuando?); 16) Trabalhos que estudem a relação entre as políticas internacionais e as políticas nacionais e locais acerca das definições sobre a Gestão Ambiental Pública; 17) Pesquisas que abordem as questões epistemológicas referentes às políticas públicas de EA; 18) Trabalhos que enfoquem as diversas formas de privatização das políticas públicas de EA; 19) Investigações centradas nas conquistas em relação à construção da Gestão Pública Ambiental no Brasil; 20) Pesquisas que investiguem os processos de formulação e implementação das políticas e programas municipais e estaduais de EA; 21) Investigações sobre os limites e possibilidades de fortalecimento da democracia nos processos de formulação da Gestão Ambiental Pública; 22) Trabalhos que investiguem o regime de colaboração entre instituições públicas para a organização da Gestão Pública Ambiental. 
A partir desses temas de pesquisa, uma série de questões foi listada pelos pesquisadores participantes do GDP. Essas questões poderão servir como uma orientação inicial, sobretudo aos jovens pesquisadores recém ingressos no campo da educação ambiental que estejam interessados em investigar na área das políticas públicas. Ao todo, foram elencadas treze questões:

1. O que estamos entendendo por gestão ambiental pública?

2. Quais são os instrumentos necessários para a gestão ambiental pública?

3. Como as políticas públicas têm identificado os sujeitos prioritários de suas ações?

4. Quem vem formulando as políticas públicas?

5. Qual a relação entre as políticas internacionais, nacionais e regionais?

6. Quais são as questões epistemológicas que permeiam as pesquisas sobre Educação Ambiental e as Políticas Públicas?

7. Quais as estratégias de privatização da gestão ambiental em curso no país?

8. Quais são as conquistas no período democrático para a gestão ambiental pública?

9. Quais são as diferenças entre o dito e o realizado nas políticas públicas para a gestão ambiental?

10. Quais são os limites e dificuldades para a realização da gestão ambiental pública na atualidade?

11. Como tem ocorrido o diálogo entre as instituições responsáveis pela gestão ambiental pública?

12. Como vêm sendo definidas as políticas municipais e estaduais de gestão ambiental pública?

13. Quais são os referenciais teórico-metodológicos do campo de pesquisa em políticas públicas que podem ser aproveitados em pesquisas sobre a gestão ambiental?

As questões propostas pelos pesquisadores participantes refletiram uma preocupação que permeou a maioria dos trabalhos. Embora o conjunto das pesquisas inscritas no GDP tenha sido caracterizado pela diversidade de temas e objetos empíricos, parte significativa dos trabalhos (Tr032, Tr015, Tr207, $\operatorname{Tr} 012, \operatorname{Tr} 132, \operatorname{Tr} 178)$, ou seja, 42,80\%, analisaram problemas relacionados à gestão ambiental pública. Assim, os debates travados no GDP, durante o VIII EPEA, focaram no tema relativo à gestão ambiental pública, seus condicionantes e desdobramentos, frente a uma conjuntura de reforma gerencial da administração das agências estatais, iniciada ainda na década de 1990, em todos os níveis do Estado brasileiro. Nesse sentido, uma preocupação fundamental, que orientou parte dos debates do GDP na respectiva edição, esteve vinculada à necessidade de qualificar a participação da sociedade civil, considerando o caráter heterônomo da ordem capitalista, em geral, e nos países periféricos, em particular.

A gestão ambiental pública no Brasil se estruturou e reestruturou numa conjuntura de redemocratização do país. Essa conjuntura, mesmo marcada por muitos retrocessos, foi caracterizada no campo ambiental pela organização de uma avançada legislação e pela instituição de um conjunto de agências estatais que tem sido disputado no processo histórico. Tal tema deve ser considerado, na perspectiva dos pesquisadores do GDP, em sua natureza enquanto espaço político-pedagógico de conflito. Espaço, este, que deve ter como horizonte, no enfrentamento dos conflitos, uma sociedade verdadeiramente democrática. Para tanto, o caráter público, democrático da gestão precisa ser permanentemente buscado.

No atual contexto de recomposição burguesa (MÉSZÀROS, 2009), frente à crise do modelo de acumulação, os instrumentos de mediação dos conflitos de classe, incluindo o próprio Estado, vêm sendo reorganizados e, nesse mesmo sentido, a presença e participação dos representantes dos interesses dominantes no interior da administração pública tem sido intensificadas. Contextualizadas nessa conjuntura, as investigações realizadas por meio de 
pesquisa que sistematize e analise os movimentos, conflitos e contradições presentes nas instituições públicas poderão oferecer fundamental importância, no sentido do fortalecimento de políticas que favoreçam as condições de existência e satisfação dos trabalhadores em sua luta pela emancipação.

Nesse processo de entendimento da gestão como espaço político-pedagógico, o pesquisador deve estar atento aos elementos que corroborem a efetiva participação das pessoas de modo a garantir o devido controle social. E, sob esse aspecto, é importante considerar em que medida as políticas públicas transitam para uma política de Estado? Evidentemente, não se trata de qualquer Estado, mas de um Estado de direito, participativo e democrático, embora organizado em um contexto histórico marcado pelas contradições que estruturam nossa sociedade. O que muitas vezes parece estar invisível, o pesquisador deve tornar visível pela mediação do conhecimento produzido na análise dos dados investigados. A partir desse movimento, o pesquisador desnaturaliza o Estado e as políticas públicas, identificando, nestes, as disputas, conflitos, negociações e consensos produzidos entre os agentes, coletivos e individuais, em luta.

Além disso, as pesquisas desenvolvidas sobre a temática aqui destacada, devem considerá-la em sua complexidade e, para tanto, é necessário dar mais atenção, como sugere Phillip Payne (2009), à tríade ontologia-epistemologia-metodologia no delineamento das investigações. $\mathrm{O}$ aprofundamento teórico e o compromisso com a pesquisa vêm fortalecendo o GDP no decorrer das edições do EPEA e, nos próximos anos, a responsabilidade dos pesquisadores que compõe este grupo será ainda maior frente à onda conservadora que predomina no país e no mundo. O conhecimento sistematizado, produzido em acordo com os interesses públicos da sociedade brasileira, deverá ter papel ainda mais relevante nesse contexto.

Na edição do GDP aqui referenciada, foi identificada pelos pesquisadores outra questão importante que deverá ser considerada pela agenda de pesquisa nos próximos encontros. O debate sobre as políticas públicas no campo de educação ambiental deve considerar a interface com a produção acadêmica de outras áreas do conhecimento, incluindo os trabalhos realizados no próprio campo de pesquisas em educação, destacando-se aqueles que resultam de análises sobre as políticas públicas educacionais desenvolvidas nas últimas décadas. A interlocução com as demais áreas do conhecimento propicia aos pesquisadores uma fértil revisão sobre a produção acadêmica nacional e internacional, em um diálogo epistemologicamente profícuo.

As questões elaboradas no âmbito do GDP sinalizam o interesse em aprofundar as investigações, de modo a explicitar aspectos contraditórios da formulação das políticas públicas, as relações entre aspectos internacionais, nacionais e regionais, os avanços democráticos, os limites impostos pelo contexto histórico de implementação das políticas públicas, a atuação das classes sociais, os elementos teóricos e epistemológicos do campo de pesquisas em educação ambiental e políticas públicas.As políticas públicas em educação ambiental, no decorrer dos últimos trinta anos, foram formuladas e implementadas num contexto sócio-histórico de profundo retrocesso para os direitos sociais. O conjunto de pesquisas apresentadas nesta última edição, no âmbito do GDP, demarca o interesse dos pesquisadores que compõem o grupo na direção de compreender os limites e avanços conquistados no período democrático, ressaltando o compromisso com o aprofundamento teórico e epistemológico.

Considerando, ainda, a diversidade na formação intelectual dos pesquisadores da área de educação ambiental, ou seja, tais pesquisadores são formados/graduados em diferentes áreas do conhecimento, há que se ter, além do foco temático, uma necessária e permanente relação com pesquisas desenvolvidas na área de ciências políticas, ciências sociais e de 
núcleos interdisciplinares de investigação sobre políticas públicas. Além disso, cabe lembrar, conforme afirma Souza (2006, p. 25):

As políticas públicas repercutem na economia e nas sociedades, daí por que qualquer teoria da política pública precisa também explicar as inter-relações entre Estado, política, economia e sociedade. Tal é também a razão pela qual pesquisadores de tantas disciplinas - economia, ciência política, sociologia, antropologia, geografia, planejamento, gestão e ciências sociais aplicadas partilham um interesse comum na área e têm contribuído para avanços teóricos e empíricos.

Os pesquisadores da área de Educação Ambiental que buscam aprofundar suas pesquisas sobre a temática das Políticas Públicas precisam estar atentos à natureza e peculiaridades dessa temática, bem como ao movimento de inter-relação com pesquisadores das outras áreas que a investigam. Esse movimento, segundo Loureiro (2012), é parte do amadurecimento do campo de pesquisas em educação ambiental e políticas públicas, devendo ser ponto de reflexão nas próximas edições do GDP. O compromisso dos pesquisadores do grupo legitima esse fórum como parte fundamental na socialização da produção pública de conhecimento produzido nos programas de pós-graduação do país.

\section{Considerações finais}

Acompanhando o processo de discussão sobre Pesquisas em Educação Ambiental e Políticas Públicas no âmbito do GDP constituído no interior do EPEA, podemos perceber que, embora não haja uma ampliação crescente do número de pesquisas, pois há uma oscilação de um evento para outro, as pesquisas realizadas sobre essa temática, no entanto, são permeadas por uma ampliação de subtemas relacionados a ela. De um evento para outro, novos temas são investigados e, ao mesmo tempo, na discussão do GDP, novos desdobramentos temáticos são sugeridos para a investigação. A lista de proposições temáticas é ampliada a cada evento. Tal fato demonstra a potencialidade de investigação acerca da temática. E, em se tratando de pesquisas realizadas na área de educação ambiental, tal fato pode ser derivado da necessidade de se estabelecer e de fortalecer relações e compreensões da temática das políticas públicas presentes em pesquisas de áreas com maior tradição de pesquisa com aquelas que são desenvolvidas no campo, em processo de construção, da educação ambiental.

A visível ampliação temática constatada deve ser, também, permeada nas pesquisas desenvolvidas, pela explicitação e pelas compreensões dos conflitos políticos e epistemológicos que a acompanham. Tal é o desafio que deve ser considerado e enfrentado pelos pesquisadores dessa temática no processo de construção do campo de pesquisa sobre educação ambiental no Brasil.

\section{Referências}

ANELLO, L. de F. S. Os programas de Educação Ambiental no contexto das medidas compensatórias e mitigadoras no licenciamento ambiental de empreendimentos de exploração de petróleo e gás no bar do Brasil: a totalidade e a práxis como princípio e diretriz de execução. 2009. 177fls. Tese (Doutorado em Educação Ambiental), Universidade Federal do Rio Grande.

CARVAlHO, I. C. M. Qual Educação Ambiental. Agroecologia e Desenvolvimento Rural Sustentável. Porto Alegre, v.2, n.2, abr./jun. 2001.

CARVALHO, I. C. M. Educação ambiental: a formação do sujeito ecológico. São Paulo: Cortez, 2004. 
FERRARO JR., L. A. Dialogar e digladiar: entre a conflagração e a constituição do campo da pesquisa sobre políticas públicas de educação ambiental. Pesquisa em Educação Ambiental, Rio Claro, v. 7, n. 2, p.133-145, Jul./Dez. $2012 . \quad$ Disponível em: http://www.periodicos.rc.biblioteca.unesp.br/index.php/pesquisa/article/view/6866/4969 Acesso em 14 abr. 2016.

GUIMARÃES, M. A formação de educadores ambientais. Campinas: Papirus, 2004.

GUIMARÃES, M.; OLABARRIAGA, N.; TONSO, S. A pesquisa em políticas públicas e Educação Ambiental. Pesquisa em Educação Ambiental, Rio Claro, v.4, n.2, p.215-227, Jul./Dez. 2009. Disponível

em: http://www.periodicos.rc.biblioteca.unesp.br/index.php/pesquisa/article/view/6202/4550 . Acesso em 14 abr. 2016.

LAMOSA, R. de A. C. A educação ambiental e o novo padrão de sociabilidade do capital: um estudo nas escolas de Teresópolis (RJ). 2010, 176 fls. Dissertação (Mestrado em Educação) - Universidade Federal do Rio de Janeiro, Rio de Janeiro, 2010.

LAYRARGUES, P. P. A conjuntura da institucionalização da Política Nacional de Educação Ambiental. In: OLAM: Ciência \& Tecnologia, ano II, v.2, n.1, Abril de 2002 (Formato Eletrônico: CD-ROM).

LAYRARGUES, P. P. e LIMA, G. F. da C. Mapeando as macro-tendências político-pedagógicas da Educação Ambiental contemporânea no Brasil. In: Encontro Pesquisa em Educação Ambiental, VI, 2011, Ribeirão Preto, Anais VI EPEA, Ribeirão Preto, 2011. CD-ROM, p. 1-15.

LAYRARGUES, P. P. Para onde vai a educação ambiental? O cenário político-ideológico da educação ambiental brasileira e os desafios de uma agenda política crítica contra-hegemônica. In: Revista Contemporânea da Educação. vol. 7. n.14, ago/dez. 2012.

LOUREIRO, C. F. B. (org.) Educação ambiental e gestão participativa em unidades de conservação. Rio de Janeiro, Ibase, 2003.

LOUREIRO, C. F. B. et.al. (orgs.) Educação Ambiental: repensando o espaço da cidadania. $3^{\text {a }}$ Ed. São Paulo: Cortez, 2005

LOUREIRO, C. F. B. Sustentabilidade e Educação: um olhar da ecologia política. São Paulo: Cortez, 2012.

MÉSZÁROS, I. A crise estrutural do capital. São Paulo: Boitempo, 2009.

PAYNE, P. G. Framing Research: Conceptualization, Contextualization, Representation and Legitimization. Pesquisa em Educação Ambiental, Rio Claro, v.4, n. 2, p. 49-77, Jul,/Dez. 2009. Disponível

em: http://www.periodicos.rc.biblioteca.unesp.br/index.php/pesquisa/article/view/6191/4539. Acesso em 12 mai. 2016.

QUINTAS, J. S. Introdução à gestão ambiental pública, 2. ed. rev. Brasília: IBAMA, 2006.

QUINTAS, J. S. Educação no processo de gestão ambiental pública: a construção do ato pedagógico. In: LOUREIRO, C. F. B., LAYRARGUES, P. P. e CASTRO, R. S. (orgs) Repensar a Educação Ambiental: um olhar crítico. São Paulo: Cortez, 2009.

SANTANA, L. C. Pesquisa em Educação Ambiental e Políticas Públicas: apontamentos e memória de um processo. Pesquisa em Educação Ambiental, Rio Claro, v.9, n.1, p. 156-168, Jan./Jul. 2014. 
Disponível

em:

http://www.periodicos.rc.biblioteca.unesp.br/index.php/pesquisa/article/view/9188/6316. Acesso em 14 abr. 2016.

SOUZA, C. Políticas Públicas: uma revisão da literatura. Sociologias, Porto Alegre, Ano 8. n.16, p. 20-45, Jul./Dez. 2006.

SORRENTINO, M. et al. Educação Ambiental como Política Pública. Educação e Pesquisa, São Paulo, v. 31, n. 2, p 285-299, 2005

TOZONI-REIS, M. F. de C., TEIXEIRA, L. A., MAIA, J. S. de S. As publicações acadêmicas e a educação ambiental na Escola Básica. In: Reunião Anual da ANPEd 34a , 2011, Natal, ANAIS, 2011. p. 1-11. Disponível em: 34reuniao.anped.org.br/images/trabalhos/GT22/GT22-257\%20int.pdf Acesso em 15 abr. 2016 